\title{
¿Sirve la formación para tener empleo?*
}

\section{A. M artín Artiles \\ Andreu Lope}

Universitat Autònoma de Barcelona. D epartament de Sociologia. Grup Q UIT 08193 Bellaterra (Barcelona). Spain

\section{Resumen}

Estudio de casos. Investigación empírica sobre la formación «para» acceder al empleo y la formación «en» el trabajo. Crítica al concepto de formación en la teoría del capital humano.

Palabras clave: formación, formación «en» el trabajo, cualificación, empleo, capital humano.

\section{Abstract}

Cases studies. Empirical research on training and employment and also training on-thejob. A critical apraach to the concept of training in Theory of H uman C apital.

Key words: training, training on the job, skills, employment, human capital.

\section{Sumario}

1. Introducción

2. Formación «para» el acceso al empleo

3. Formación «en» el trabajo
4. Trayectorias vitales y estrategias laborales

5. Conclusiones

Bibliografía

* Este artículo es el resultado de una investigación financiada por la DIGICYT. En este proyecto, dirigido por Faustino M iguélez, han participado Carlos Lozares, Pedro López, Joan M iquel Verd, Joel M artí y Clara Llorens. Por tanto, las ideas que se exponen en el presente artículo constituyen también una contribución colectiva y debatida en el seno del propio grupo.

Una versión de este estudio fue presentada en el Congreso de Sociología, celebrado en La Coruña, 25-27 de septiembre de 1998. 


\section{Introducción}

D esde mediados de la década de los ochenta se ha venido impulsando la idea, desde las distintas instancias gubernamentales, de que la formación tiene un importante papel para acceder al empleo. Incluso, en los Acuerdos de Essen de 1994, la Comisión Europea recomienda a los gobiernos incluir la formación como parte de las políticas activas de empleo. El discurso de la formación se ha ido transformando en una especie de ideología e imponiendo como parte de las estrategias gubernamentales frente al paro. Ello ha dado lugar a la extensión de distintas iniciativas institucionales para impartir formación para los desempleados. Asimismo, ha dado lugar a la proliferación de cursos formativos y de reciclaje de los trabajadores en las empresas. La formación y la cualificación se han convertido en las claves «para» acceder al empleo y mantenerse «en»él.

Frente a este discurso dominante, iniciamos un proyecto de investigación a partir de una perspectiva crítica, o cuanto menos dudosa, sobre el bondadoso papel de la formación «para» acceder al empleo o bien para mantenerse «en» él. Entonces, en el inicio del proyecto, nos asaltaban algunos interrogantes, tales como ¿realmente la formación tiene este papel tan determinante en el acceso y/o mantenimiento del empleo? ¿Q ué formación para qué empleo? Responder a estas preguntas no es fácil, ni aquí nos proponemos contestar de forma exhaustiva a dicha cuestión. Con todo, contestar razonablemente a estos interrogantes nos llevó a plantearnos cinco retos.

El primer reto consistió en responder a la pregunta sobre qué papel tiene la formación reglada en el acceso al empleo, así como el papel que tiene el «capital relacional» en la intermediación entre oferta y demanda en el mercado de trabajo. El segundo reto fue tratar de explicar los usos y significados del concepto de formación para los oferentes y para los demandantes de empleo. El tercer reto fue tratar de dar cuenta del decalage entre formación reglada, formación exigida y requerimientos de los puestos de trabajo. Dicho de otro modo, entre la titulación académica, la demanda de formación en el momento de la contratación y la cualificación efectiva en el desempeño del puesto de trabajo. La cuarta cuestión consistió en proponer una redefinición del concepto de formación, en la precisión de sus límites y de sus eventual es implicaciones téoricas y prácticas. Y, finalmente, el quinto reto consistió en debatir de nuevo con el discurso dominante sobre el papel de la formación, así como con las teorías que abordan su relación con el empleo.

A estos retos no queríamos contestar de forma abstracta con otro discurso opuesto, sino a partir de una investigación empírica que nos permitiera contrastar algunas hipótesis. La investigación consistió en tres pasos. En primer lugar, se llevó a cabo un estudio contextual con la finalidad de obtener un mapa de las características socioeconómicas de una determinada comarca. Elegimos el Vallès 0 ccidental por su importante volumen de población, empleo y dinamismo en la actividad económica. I gualmente, se estudio la evolución del empleo y la política educativa de la misma. A partir de las características 
del contexto, en segundo lugar, escogimos dos empresas significativa del mismo, una empresa industrial - textil, muy característica de la comarca - y otra de servicio - hipermercado o gran superficie comercial- , actividad emergente en la comarca y que tiene un importante papel en la cración neta de empleo. $Y$, en tercer lugar, pasamos a estudiar las estrategias formativas de los trabajadores y la política formativa de las empresas. A tal efecto se pasó un cuestionario a la plantilla de empleados, se realizaron entrevistas en profundidad con algunos de ellos para estudiar su trayectoria biográfica y se entrevistó a la dirección de las empresas.

En las siguientes páginas tratamos de dar cuenta de la respuesta a los retos ya mencionados. Primero de forma más general, en base a tratar el papel de la formación «para» el empleo y la formación «en» el empleo. D espués, en las conclusiones, trataremos de responder a cada reto teórico de forma más concreta y pormenorizada.

\section{Formación «para» el acceso al empleo}

D esde el punto de vista de la demanda, que se plasma en las políticas de reclutamiento laboral de las empresas, el concepto de formación tiene un carácter difuso, de contornos imprecisos. La exigencia de formación reglada, en los términos que plantea la teoría meritocrática, no es determinante. El mérito de la certificación escolar no es suficiente, pero sí actúa como mecanismo de preselección en el acceso, de modo que, en algunos casos, la formación reglada es una condición necesaria, aunque no suficiente, para acceder a determinados empleos. Para captar el significado del uso del concepto de formación desde la óptica de la demanda, es necesario detenerse en los criterios de reclutamiento, selección y formación de las empresas estudiadas.

\subsection{Intermediación y reclutamiento de la fuerza de trabajo}

El reclutamiento de la mano de obra está estrechamente ligado a la intermediación de las redes sociales del entorno. En el caso de la empresa textil, el 39\% de los trabajadores contratados a lo largo de los años noventa obtuvo información sobre el empleo que acabaría ocupando a través de vías familiares y amicales 1 ; en la gran superficie comercial, las redes familiares y de amistad han supuesto el $36 \%$ de las vías de entrada. En principio no debe extrañar el importante peso de las redes sociales en el acceso al empleo, máxime si tenemos en cuenta el entorno social que nos ocupa2. Tampoco deben extrañar demasiado las diferencias entre ambas empresas.

1. Puesto que carecería de sentido indicar datos de reclutamiento referidos a trabajadores que ingresaron en la empresa hace varias décadas, los datos indicados en este apartado para la empresa textil están basados únicamente en los contratos realizados a partir de 1990.

2. En efecto, las empresas estudiadas están rodeadas de un entorno que parece propiciar la formación de redes sociales. La estructura de ese entorno se caracteriza por unos niveles educativos inferiores a la media de Cataluña, y por un nivel muy importante de población 
La de acabados es una «pyme» con un historial enraizado en la tradición productiva textil de la comarca. Cuenta con un gerente/ empresario de talante paternalista, que está vinculado al G remio de Fabricantes del textil de la zona y a la escuela de formación ocupacional que depende del mismo y que es, a su vez, el principal accionista de otras empresas del ramo. Por ello, los mecanismos de reclutamiento y selección, basados en las referencias que proporcionan las redes, no se circunscriben solamente a redes amicales y familiares, sino también a otras vías más sofisticadas que han aumentado significativamente su importancia en los últimos años; nos referimos a las «redes empresariales». Efectivamente, el $28 \%$ de los contratados en los años noventa declara haber entrado en la empresa porque ésta o la empresa en la que trabajaba anteriormente se lo propuso. En otros casos, los nuevos contratados han sido seleccionados por la escuela de formación del Gremio de Fabricantes, a solicitud de la empresa. Estas nuevas formas de reclutamiento no son más que la institucionalización de un sistema de redes que permite a la empresa contar con una «bolsa de trabajo» que le propociona canales para, de ser necesario, proceder a la selección del personal necesario.

El hiper, por su parte, no tiene ninguna tradición en la zona. Se crea en 1990 y resulta una empresa «importada», lo que comporta la ausencia de unos filones de reclutamiento tradicional sedimentados en la zona. Eso conlleva, en los inicios de su actividad, el uso de mecanismos más genéricos, como el recurso al IN EM , al anuncio, o utilizar el boca a boca que provoca la noticia de la creación de un hiper para acceder directamente a sus dependencias en busca de empleo. Como muestra del peso de este último factor, la estrategia de acudir directamente a la empresa en busca de empleo fue seguida por el $29 \%$ de los empleados del hiper, proporción que se reduce a menos del $6 \%$ en la industria textil.

Además, las propias empresas crean «bolsas» de trabajo propias mediante sistemas de reclutamiento informales. A través de visitas de colegios o institutos (como ocurre en el hiper), o de contactos con escuelas de oficios y centros de formación profesional (como sucede en la textil). 0 tras veces las propias empresas abren carpetas de solicitudes de trabajo que utilizan en ocasiones cuando lo necesitan.

También se puede observar, a través de las entrevistas, la existencia de redes sociales «internas» que proporcionan contactos de calidad o de información privilegida. Se trata de redes formadas a partir de los propios trabajadores de la empresa y sus círculos inmediatos: familias, parientes, amigos y

de origen inmigrante. Esta población se concentra en unos determinados barrios obreros periféricos de Sabadell, hecho que propicia un entorno favorable a la formación de redes social es basadas en el parentesco, la amistad y la vecindad. A eso hay que añadir la existencia de una estructura económica basada en la pequeña empresa, que conforma y caracteriza un mercado de trabajo secundario. Estas condiciones estructural es favorecen la circulación de la información a través de las redes sociales existentes, especialmente aquélla que hace referencia a los puestos de trabajo secundarios. Todo ello incide en el acceso al empleo, primando un tipo de relaciones con la fuerza de trabajo de carácter paternalista o clientelar. 
vecinos. Estas redes proporcionan ventajas de información y mayores posibilidades de acceso al empleo. Los trabajadores conocen directamente las vacantes que se registran en la empresa y transmiten a sus círculos familiares y amicales tales previsiones de empleo. C abe añadir, desde el punto de vista de la empresa, que las redes sociales facilitan la reducción de los costes de selección, además de otras ventajas no desdeñables. En efecto, para ella también son importantes esas redes por cuanto aceleran el proceso de búsqueda y selección de personal, proporcionan tácitamente confianza y lealtad y facilitan la contratación verbal e informal, además de la aludida reducción de los costes de selección 3 .

En particular, las redes son especialmente importantes para los puestos de trabajo de inferior categoría. Así parece también desprenderse de los datos de las encuestas realizadas. En el caso del hiper, las personas con mayores niveles de estudios utilizan algo menos las redes familiares y de amistad y más los anuncios y procedimientos formalizados. En cuanto a la edad, son los más jóvenes los que preferentemente utilizan las redes familiares, lo que concuerda con las tendencias ya observadas en otros estudios (véase, entre otros, Requena, 1990).

El reclutamiento de la fuerza de trabajo a través de otros canales públicos (IN EM y Servei Català de Col·locació) es desigual según la empresa. En el caso de la textil sólo uno de los dieciocho contratos realizados en los años noventa se ha iniciado por esta vía. En cambio, en la gran superficie comercial representa un 23\%, lo que se explica, fundamentalmente, por lo reciente de su apertura y por el uso, en aquellos momentos, de ese mecanismo. Por otra parte, conviene significar que, en el hiper, el reclutamiento de cajeras y jefes de sección está asociado a la recepción de procesos de formación previos en la empresa que actúan, de al gún modo y entre otras funciones, como «ritual de transición» al empleo.

El reclutamiento a través de anuncios es poco significativo en la empresa textil (un sólo caso), mientras que en la comercial es algo más importante (8\%). En todo caso, parece que en las dos empresas la contratación a través de anuncios surge cuando no es posible hacerlo a través de las redes sociales ni de las instituciones públicas, o cuando se demandan cualificaciones muy precisas. Por último, la intermediación privada tiene también poco peso y, en el hiper, se usa sólo como elemento complementario para las categorías de jefatura. Q uizás es más importante en la empresa textil, donde desde hace unos años los pocos contratos que se realizan se ligan al uso de pruebas psicotécnicas. En cualquier caso, en esta empresa priman el currículum, la entrevista y las referencias, aunque en los nuevos contratos de trabajadores de producción tienen más importancia éstas últimas. Así, la presencia más específica del currículum y la mayor

3. De hecho las relaciones de parentesco tienen también un importante papel como mecanismo de selección. En el caso del hiper se valora positivamente contar con un familiar empleado en la empresa cuando se trata de solicitar un puesto correspondiente a las categorías inferiores. 
importancia de la entrevista marcan la diferencia entre categorías: en las bajas no aparece el currículum y en las altas disminuye la rel evancia (en los nuevos y escasos contratos) de la entrevista, lo cual contribuye a aumentar el peso de las referencias.

\subsection{Selección de la fuerza de trabajo}

Los procesos de selección dependen de las características y de los niveles de los puestos a ocupar. La percepción subjetiva de los entrevistados no dista mucho de los criterios realmente utilizados por las empresas estudiadas. Así, en ellas el nivel educativo no es determinante, sino que los criterios de selección se construyen a partir de los propios puestos de trabajo a ocupar y, en ocasiones, tienen que ver con características individuales de quienes buscan empleo alejadas de su educación formal.

En general, según perciben los propios encuestados, tiene especial importancia la presentación de referencias como criterio de selección de la fuerza de trabajo. En este orden, y como se ha indicado, destaca la empresa textil; en la que más de la mitad de la plantilla (con porcentajes superiores entre los trabajadores de producción) declara que éste fue un argumento de peso en la selección. En el caso del hiper ese peso selo atribuyen sólo el 7\% de los encuestados, aunque también aquí es mayor entre quienes ocupan las categorías inferiores. Las referencias las pueden proporcionar personas concretas u otras empresas. «Venir de parte de... » significa tácitamente un cierto compromiso en términos de lealtad, obediencia 4 y responsabilidad en el trabajo. 0 , como resumen los entrevistados, ser «cumplidor».

Los empleados son conscientes de la exigencia empresarial de «buena disposición» hacia el trabajo. Se trata de lo que los entrevistados denominan eufemísticamente «capacidad de trabajo», y que no es más que hacer más de lo exigido y más allá de la duración de la jornada laboral, con la frecuente finalidad de conseguir la renovación del contrato temporal de trabajo. D e hecho, más del $50 \%$ de los encuestados coinciden en valorar esa «capacidad de trabajo» como un elemento determinante para ser contratado o recontratado; una capacidad que la dirección de la empresa valora explícitamente y que, por otro lado, sólo puede constatarse tras un período de prueba prolongado 0 , más ususalmente, tras un contrato temporal.

También para técnicos y mandos parece ser importante proporcionar refe rencias, además de presentar el currículum. Especialmente para las ocasiones en que estos puestos de trabajo están próximos a las esferas de poder y de deci-

4. Las pautas de obediencia se aprenden durante el proceso de socialización primaria. Es decir, en buena parte, el proceso de socialización en la familia y la escuela proporciona pautas de autodisciplina para obedecer en el trabajo. Ésta es precisamente una de las funciones de la escuela - tal como indican las teorías credencialistas y de la reproducción (Bowles y Gintis, 1983; C ollins, 1989) - y que las empresas valoran tácita y a veces explícitamente. En pocas palabras, en este terreno y al margen de otras funciones, el sistema educativo enseña a obedecer en el marco de una determinada división del trabajo. 
sión, lo que, en la práctica, sucede en casos muy puntuales. Aquí es especialmente importante la lealtad, por cuanto se manejan datos e información relativamente confidenciales o rel evantes para las empresas. En cualquier caso, la entrevista personal es clave para la mayor parte de los puestos de trabajo, con la relativa excepción de los jefes de sector (altos directivos) del hiper.

El rasgo distintivo, en lo que se refiere a criterios de selección, es que para las categorías medias y altas los aspectos formales tienen un mayor peso. Especialmente los referidos a conocimientos, currículum, concurso o test. En general, los aspectos formales tienden a tener una creciente importancia en los criterios de selección, tanto para las categorías medias y altas, como incluso para administrativos y trabajadores de producción. Se valora entonces el currículum y la formación reglada. Como mínimo, las empresas exigen conocimientos básicos de lectoescritura para facilitar el conocimiento de las instrucciones de trabajo. En los últimos años esta exigencia se eleva a niveles de BU P o FP por la abundante oferta de certificaciones de este nivel medio ${ }^{5}$. En otras palabras, la formación reglada es, en la mayoría de las ocasiones, una variable discriminante ante el exceso de oferta; aunque no siempre actúa de ese modo, a veces supone un obstáculo.

En efecto, dada la abundancia de personas con titulaciones académicas similares, las empresas seleccionan a partir del rasgo diferencial. Ese rasgo diferencial suele ser la formación no reglada (estudios de informática, idiomas, etc.). Empero, cabe matizar también que en muchos casos un nivel educativo alto puede comportar problemas de adecuación al puesto desempeñado. Dicho de otro modo, la sobreeeducación puede alimentar el rechazo al trabajo y generar expectativas de mejora o de cambio. Las empresas son conscientes también de estos riesgos. D e ahí que los criterios de selección no siempre prioricen el nivel de educación inicial, sino las pautas de obediencia, disciplina o incluso los condicionantes familiares que garantizan el control del comportamiento 6 .

En otras palabras, los criterios de selección no siempre priorizan o tienen en cuenta el nivel de formación inicial o un plus de formación diferenciada del ofertante. En determinados puestos de trabajo pesan más las cualificaciones actitudinales y comportamentales. Esto es especialmente importante cuando los puestos de trabajo a cubrir tienen un contenido relacional por estar vinculados con actividades cara al público. Tales puestos son particularmente numerosos en el hipermercado. Y entre las cajeras que respondieron a la encuesta son clara mayoría las que creen que se valora en gran medida el «saber relacionarse», subrayando también la importancia entre los criterios de selección para el puesto de la «presencia física». Por contra, para el puesto de reponedor

5. O bsérvense los datos de la EPA en relación con el incensante incremento de parados con estudios medios finalizados. Sólo entre 1990 y 1997 el incremento de parados con estudios medios pasó de 1.303.010 a 2.071.200.

6. Elocuencia brutal de ello es la afirmación de que «as mujeres casadas con hijos y con pocos estudios son las más rentables» y adaptables al puesto de cajeras en el hipermercado. 
se da una mayor importancia a la experiencia. En otras palabras, los criterios de selección presentan a veces un marcado sesgo en razón del género. Se apoyan, entonces, en el estereotipo de las capacidades atribuidas a las mujeres, como es atender a los demás, en este caso al público. En este sentido, se valoran capacidades y actitudes como la comunicación no verbal, el contacto visual, saber sonreir, dar las gracias y despedirse de forma adecuada y correcta. Es más, como hemos visto para el hiper, incluso los complementos salarial es están asociados al seguimiento de estas actitudes; actitudes que configuran parte de los reque rimientos pautados del puesto de trabajo.

Por otro lado, la titulación superior muchas veces no se valora por su propio contenido ni por el perfil profesional que dibuja, sino por lo que se presupone. Es el caso del hiper, que exije para todos sus jefes de sección una licenciatura en D erecho o Economía7, pese a que sus contenidos guardan escasa o nula relación con los requerimientos del puesto de trabajo y pese a que, como indica la dirección de Recursos H umanos: «cualquier persona con BUP podría hacer ese trabajo después de ser formado - como ocurre con los licenciados- en la empresa».

$O$ tro tanto sucede en la empresa textil. Para los puestos de categorías supe riores, con exigencias de capacidades de planificación, organización, dirección y relación, la titulación opera como un contenido cuyo «valor se le supone» en dichas funciones; esto es, se acepta que su detentor posee aquellas capacidades. Por eso precisamente el contenido del título no tiene una importancia decisiva, pudiendo encontrarse personas que ocupen esas funciones prque poseen aquellas cualidades sin tener un grado superior de titulación. Eso se observa en los casos en los que los conocimientos supuestos mediante la credencial son sustituidos por la experiencia en la propia empresa, como ocurre con los encargados. En el hiper la titulación tiene, además, el papel de mecanismo de selección para los jefes de sección; mientras que en la textil, en las funciones técnicas derivadas de los cambios productivos introducidos en los últimos años (por ejemplo en el control de calidad, o en el laboratorio), se da una correspondencia entre las mismas y el contenido del título.

En cualquier caso, independientemente del perfil de las titulaciones, se suelen contratar titulados superiores para tareas de coordinación de equipos, mandos intermedios, supervisores y controladores. D e ese modo, se presupone que las titulaciones superiores universitarias están implícitamente asociadas a habilidades de sistematización, ordenación, capacidad de abstracción, perspectiva global sobre el conjunto de la actividad, dotes de coordinación, mando y lide razgo. En ese sentido, y en la práctica, para muchas empresas podrían ser ade cuadas titulaciones con perfiles genéricos.

7. Algunas investigaciones, como la de M asjuan y otros (1996), ponen de relieve que las titulaciones universitarias que contienen un perfil reconocido en el mercado de trabajo son, precisamente, D erecho y Economía. El resto de las C iencias Sociales y H umanidades tienen perfiles más difusos y menos reconocidos. O tra consideración y aún mayor reconocimiento tienen también las ingenierías (excepto la agrícola), véase también Alvaro Espina (1997). 


\subsection{Papel dela formación «para» el acceso al empleo}

En definitiva, la formación reglada no tiene un papel tan determinante en el acceso al empleo como sostiene la teoría del capital humano. El mérito acumulado en el sistema educativo puede ser una condición de creciente importancia en las políticas de reclutamiento y selección de la fuerza de trabajo, como consecuencia del aumento del nivel general educativo de la población8. La educación hace la función de criba. Por tanto, podemos hipotetizar que la abundancia de titulaciones medias y superiores desplazan hacia el desempleo a los colectivos de menor nivel educativo. Sin embargo, este mayor nivel educativo no se traduce en puestos de trabajo cualificados, en tanto que las empresas contratan trabajadores con niveles educativos superiores a la cual ificación exigida por el trabajo a desempeñar. D e ahí la percepción objetiva (derivada de la obervación de puestos de trabajo que hemos realizado) y subjetiva (de la casi totalidad de los entrevistados) de un exceso de formación reglada para, finalmente, realizar tareas que son básicamente de tipo normativo, prescritas y estandarizadas en base a una determinada racionalización taylorista del trabajo.

Por otra parte, el abandono de los estudios o los estudios inacabados, no necesariamente impiden el acceso a empleos del tipo que ostentan la mayor parte de los entrevistados. Ese acceso se hace posible a través de las redes sociales de parentesco, amistad y vecindad; así como a partir de las exigencias que realmente recaban las empresas para el desempeño laboral. Sin embargo, el abandono de los estudios (especialmente en niveles primarios y secundarios) condiciona negativamente el acceso a determinados empleos, aunque los conocimientos que se adquieran en estos estudios no sean necesarios para el desempeño de las tareas. Así, la credencial que proporciona la formación reglada es valorada por las empresas, puesto que con ella se supone que se certifica la interiorización de determinadas actitudes y pautas asociadas a la subcultura de clase, tales como la subordinación, obediencia, disciplina y puntualidad. El abandono de la formación reglada primaria o secundaria tiende a asociarse, por parte del empresario, a una rebel día frente a esas actitudes. Actitudes que la empresa exige para cubrir unas determinadas vacantes de empleo, definidas según una precisa y determinada división y racionalización del trabajo. D icha racionalización, aunque hoy esté puesta en cuestión, no sólo es propia de la industria, sino también - y crecientemente- de los servicios (véase Ritzer, 1996). En otras palabras, tanto en la industria como en los servicios existe una marcada tendencia a estandarizar las tareas a través de normas que prescriben su contenido. D e facto, en las dos empresas estudiadas los requerimientos de cualificación de la gran mayoría de puestos y categorías laborales tienen como prioridad el cumplimiento preciso de las normas asignadas a cada función.

8. D e hecho, ésta es una de las explicaciones de la «teoría de la cola». La credencial académica sirve, básicamente, para saltarse unos cuantos puestos de la cola y avanzar en la hilera de candidatos al empleo. 
En cualquier caso, eso no comporta dejar de lado las capacidades aportadas por el sistema educativo. H emos señalado ya que certifican, al menos simbólicamente, la adquisición de determinadas actitudes. Pero, además, un mínimo de formación reglada es imprescindible, incluso para el desempeño de funciones laborales de poca complejidad. La empresa es consciente de que hasta la adaptación a un puesto de trabajo simple es más fácil de obtener si se cuenta con al gún nivel educativo. I gualmente, contar con titulaciones superiores, se entiende como sinónimo de capacidad de aprendizaje, lo que sirve para argumentar el interés de contar con titulados universitarios para determinadas funciones laborales.

Precisamente respecto a las titulaciones superiores, cabe subrayar aquí dos cuestiones. La primera, es que se suelen contratar independientemente de su contenido; con excepciones como las de la empresa de acabados, cuyos contados licenciados lo son en carreras vinculadas, al menos relativamente, a la función laboral que desarrollan. La contratación se basa en la hipótesis de que los titulados universitarios, por el mero hecho de culminar una carrera, tienen capacidad de abstracción, autodisciplina, capacidad de autoorganización y son capaces de proponerse objetivos y seguirlos sistemáticamente. Esas dotes les hacen capaces de comprender el funcionamiento global de la organización $y$, por tanto, asumir niveles de responsabilidad.

La segunda cuestión es que a los titulados superiores se les suel e contratar para funciones de coordinación, supervisión y control. Ello se debe básicamente al uso simbólico de la titulación universitaria: como distinción de estatus y no sólo como cualificación efectiva. Esta práctica supone la exigencia de modales y usos lingüísticos para dirigir pequeños grupos o coordinar distintas actividades, o para relacionarse con sumistradores y clientes externos. Estos tipos de tareas parecen comportar la búsqueda de elementos distintivos (lenguaje, gestos, comunicación no verbal, vestimenta) que contribuyan a reforzar las relaciones de poder y autoridad en la organización. D e este modo, la formación reglada es un símbolo de distinción necesario para justificar y reforzar el organigrama jerárquico de la empresa9. Un símbolo asociado al poder, que no parece justificarse como requisito concreto del puesto de trabajo. D e hecho, los puestos ubicados en un nivel jerárquico medio los podrían desempeñar personas con menor nivel educativo. D e todos modos, quizás no se puede trasladar mecánicamente esta argumentación a la industria. Como hemos señalado para la empresa de acabados, en ella los conocimientos técnicos de las titulaciones superiores tienen al go más de relación con la cualificación efectiva. Puede que al mismo tiempo también tengan el val or de símbolo distintivo, pero igualmente para desempeñar determinadas tareas de coordinación, supervisión y/o dirección es necesario conocer el proceso técnico.

9. Por otra parte, eso no implica que todos los titulados superiores ocupen puestos medios o al tos en la jerarquía de la empresa. 0 curre así en cajeras del hiper que son licenciadas y que, en otro orden de cosas, muestran una clara valoración negativa sobre su trabajo y sobre la adecuación de su nivel educativo al mismo. 


\section{Formación «en» el trabajo}

Abordaremos esta cuestión en dos partes que se complementan entre sí. En primer lugar, trataremos los mecanismos de formación informal que se aprecian en las empresas. En segundo lugar, daremos cuenta de los procesos de formación formal que tienen lugar en ellas.

\subsection{Formación informal}

La formación invisible o informal «en» el trabajo es una de las formas básicas de aprendizaje en las empresas. En el caso de la textil se pueden distinguir dos períodos. Uno, el período de aprendizaje y adaptación para los nuevos contratados; y otro, el relacionado con la introducción de nueva tecnología. D e todos modos, en ambos casos el proceso de aprendizaje es similar y, en el caso de la introducción de nuevas tecnologías, los mandos intermedios son adiestrados de forma rápida por la firma instal adora, trasladando, después, la operativa aprendida a sus subordinados. Para el grueso de los trabajadores podemos hablar, más que de formación, de adiestramiento al puesto de trabajo. Lo que se obtiene de manera informal a través de consulta a un compañero 0 al encargado de la sección. M ientras que para los cuadros técnicos el aprendizaje se apoya más en la tutorización directa y en las instrucciones de los responsables de la empresa.

En el hiper, la transmisión informal de conocimientos se apoya en mayor medida en la consulta a los compañeros, especialmente en el caso de los reponedores. El aprendizaje mediante instructor, y tras recibir una formación formalizada, es más importante en el caso de las cajeras. En las categorías intermedias sobresale también el aprendizaje a través de la consulta a un compañero y, más todavía, a un superior; siendo éste último un procedimiento igualmente presente - junto con la formación formalizada en la empresaen las categorías superiores.

La duración del adiestramiento referido al contenido del trabajo es, por lo general, breve. En los dos casos estudiados el aprendizaje se hace en un mes o menos para las categorías inferiores, con porcentajes muy significativos de casos (en trabajadores de producción de la empresa textil, reponedores del hiper, etc.) donde en menos de una semana se «aprende», de este modo, a afrontar todas las exigencias del trabajo. Por el contrario, los técnicos y mandos intermedios en la industria, y los oficiales (panadería, etc.) y cuadros medios del hiper necesitan más de un mes para poder desarrollar plenamente sus tareas. Sin embargo, el aprendizaje organizativo, más allá del propio puesto de trabajo, probablemente requiera mucho más tiempo. Este aprendizaje de la, difusamente, denominada «cultura de la empresa», forma parte de la socialización en la organización: proceso mediante el cual el individuo se hace miembro funcional de la misma. Lo que significa, además de adquirir el conocimiento de las técnicas de trabajo, interiorizar las normas, pautas y hábitos de la organización, así como adaptarse al entorno en términos socioafectivos. Por tanto, podemos colegir que el aprendizaje «en» la empresa y a tra- 
vés de la vida laboral cotidiana es más importante y duradero de lo que a simple vista parece.

Por ello las empresas suelen crear las condiciones organizativas necesarias para facilitar la transmisión de aquellos conocimientos y normas ${ }^{10}$. Las formas de transmisión son muy diversas: tutorización, acompañamiento, guía y conducción mediante trabajadores expertos (en el hiper, en ocasiones, tales «expertos» son trabajadores temporales que adiestran a los nuevos contratados cuando ellos apenas llevan unos pocos meses en la empresa) durante el proceso de aprendizaje de los jóvenes, etc. La transmisión de conocimientos es muchas veces opaca y pasa casi desapercibida porque tampoco se suele formalizar mediante la expedición de una certificación de reconocimiento11. Sin embargo, dicho aprendizaje está relacionado con el conocimiento técnico, el estilo de trabajo, los trucos y pequeñas habilidades en las tareas. Además del estrictamente referido al propio puesto de trabajo, hemos de tener en cuenta la existencia de otro tipo de aprendizaje. Consiste en el conocimiento de los hábitos, costumbres, leyes consuetudinarias, normas prescriptivas, modos de relacionarse entre los trabajadores, así como los modos de dirigirse a las jerarquías informales y formales de la empresa. Todo ello se aprende paulatinamente, de manera informal, en el día a día del trabajo, no se enseña explícitamente.

Por otra parte, si bien el aprendizaje informal técnico es carente de certificación, existe la costumbre de valorarlo como «experiencia» 0 «antigüedad». La experiencia simboliza para los trabajadores la idea de una cualificación no certificada, pero cualificación efectiva al fin y al cabo. C apacidad técnica, identidad profesional y también orgullo. La «experiencia y la antigüedad» sirven de soporte para la estructuración de los grupos y las jerarquías de poder informales en el trabajo12. En definitiva, el aprendizaje informal «en» el trabajo significa tanto el conocimiento de las tareas concretas del puesto, como conocer acumulativamente las normas no escritas y raramente explicitadas. Asimismo, el mentado aprendizaje informal cualifica tanto a los individuos como al trabajador-colectivo, de modo que podemos hablar de un saber colectivo que es

10. Este aprendizaje organizacional es también de creciente interés en las investigaciones en la sociología de las organizaciones y se refleja en el aumento de las publicaciones. Véase para más detalle, un estado de la cuestión: M oreno, 1997.

11. Esta falta de reconocimiento de la formación informal, denominada genéricamente expe riencia, se trata hoy de solventar a través del desarrollo del Sistema $\mathrm{N}$ acional de Cualificaciones previsto en el II Programa N acional de Formación Profesional. Este sistema tratará de regular el proceso de adquisición y acreditación de las cualificaciones, los contenidos de la formación y/o experiencia necesaria para acceder al título profesional correspondiente. Asimismo, se pretende que sirva como instrumento de regulación del mercado de trabajo, al definirse en los convenios colectivos y en las ofertas de empleo la cualificación requerida para los distintos puestos de trabajo.

12. Lo que se traduce en términos de antigüedad a efectos salariales. Pero detrás de la idea gené rica de «antigüedad» hay un conocimiento técnico y organizacional dela empresa. Los trabajadores valoran mucho esta noción de antigüedad, particularmente porque es una forma de defender derechos ante la carencia de la fuerza que puede dar una certificación o titulación académica. 
el resultado de la cooperación informal en el trabajo. De todo ello, podemos colegir que la formación reglada que proporciona el sistema educativo es insuficiente para desempeñar con éxito un puesto de trabajo. Siempre es necesario otro nuevo aprendizaje a través de la socialización secundaria en el trabajo, a través de la experiencia y a través de las relaciones sociales que se establecen en el trabajo. Y eso es válido para todo tipo de funciones laborales.

En efecto, el aprendizaje informal se registra en todos los niveles de la empresa. Con la particularidad que en los más bajos, el aprendizaje es fundamentalmente en el propio puesto de trabajo y de breve duración; mientras que los niveles medios y superiores necesitan un conocimiento más abstracto y una percepción más global de la organización. Por otro lado, cuanto más abstracto y genérico sea el requerimiento de abstracción más se refuerza la presencia de conocimientos formalizados en aula. D e ahí, que los programas de formación en las empresas, como hemos podido ver ya en otros estudios (Lope y M artín, 1994; M artín y Lope, 1995; Grup d'Estudis... , 1997), tengan un marcado carácter selectivo, primando a colectivos que cuentan ya con ciertos nivel es formativos formales, desempeñan tareas cual ificadas, u ocupan niveles altos en la jerarquía de la empresa.

\subsection{Formación formal «en» el trabajo}

La formación formal en el trabajo es más importante en una empresa que en otra. En el hiper es más importante porque está ligada a la política de contratación, que presenta fuertes índices de temporalidad, y sobre todo a los mecanismos de motivación que desarrolla la dirección.

En la empresa textil no se ofrecen acciones formativas para los trabajadores de producción, los oficiales o los mandos intermedios; las excepciones a esta norma son muy puntuales y poco relevantes. El comité de empresa enfatiza este hecho que, por otra parte, se contrapone a la relevancia que la dirección otorga, en su discurso, al hecho de contar con personas formadas y adaptadas a los nuevos equipos y técnicas productivas. Los directivos y técnicos sí han seguido algunos cursos externos financiados por la empresa, sobre gestión de recursos humanos (el responsable de producción) o más específicamente vinculados a sus funciones laborales (resto de casos).

En el hiper la formación tiene una importante presencia en términos cuantitativos. Podemos distinguir en ella: la que se destina a los mandos, la que se dirije a las cajeras, los cursos más concretos que siguen colectivos específicos $y$, finalmente, las acciones formativas que se destinan a toda la plantilla. Resumidamente, cabe indicar al respecto las siguientes cuestiones:

- La formación destinada a los mandos está muy estructurada a partir del seguimiento de una serie de cursos previamente delimitada. Para los jefes de sección supone un período de seis meses en los que se combinan cursos - de gestión, recursos humanos, etc. - con prácticas en el centro, seguidos después de otros cursos (una vez contratados como tales jefes de sección) pre- 
establecidos. Los jefes de sector y otros directivos siguen, asimismo, los cursos diseñados en el Catálogo de cursos para mandos, elaborado desde la empresa.

- Las cajeras siguen cursos durante tres meses que combinan, también, con prácticas laborales en lo que será su puesto de trabajo una vez contratadas. En este orden, y como ocurre con los jefes de sección, la formación adquiere aquí a los ojos de las personas implicadas una función, siquiera subsidiaria, de ritualización en el acceso al empleo.

- Colectivos específicos (al gunos reponedores, trabajadores «de oficio», de pastelería o carnicería, vendedores, etc.) reciben cursillos específicos y de corta duración, normalmente encaminados a instruirles sobre al gún nuevo producto o procedimiento.

Finalmente, hay una serie de cursos que se destinan a todo el personal. El primero supone una muy breve «formación de acogida» donde se describe el funcionamiento y la normativa de la empresa. M ás tarde, se implementan cursos que, como subrayábamos en el capítulo correspondiente a esta empresa, tienen como objetivo la integración del personal en las premisas y en la «cultura» de la empresa, sin que, por contra, tengan ningún papel en los requerimientos laborales que deben afrontar los diferentes colectivos de asalariados. A tenor de esta última consideración, y pese a que toda la plantilla ha seguido como mínimo tres, no es de extrañar que el 34\% de los encuestados afirmen no haber seguido ningún curso en la empresa. M ás aún, en el 55\% de las respuestas se indica que los que se han seguido no tienen rel evancia en términos de empleo.

La interpretación de estas respuestas es clara. Por un lado, los cursos que se destinan a toda la plantilla no tienen relación con el trabajo a desempeñar. Por otro lado, gran parte de la formación que se destina a colectivos específicos (cajeras, reponedores, etc.) se limita a insitir en el seguimiento de unas exigencias laborales ya conocidas y que, además, presentan pocas exigencias en términos de conocimientos y capacidades y más en términos normativos. Por esa razón indicábamos, párrafos atrás, que la importancia de la formación formal en el hiper es sobre todo cuantitativa. Se ofrecen numerosos cursos. Todos ellos, desde luego, subvencionados por la FO RCEM. Pero, en lo que se refiere a su calidad y vinculación con las funciones laborales, solo la que se proprociona a los mandos y - en mucha menor medida - la que inicialmente se proporciona a las cajeras, tiene relevancia.

Vale la pena advertir, por otra parte, que en el hiper la formación tiene también un rol motivador; incluyéndose dentro de los mecanismos de motivación desarrollados por la empresa. En la empresa textil la motivación se da en la práctica a través del establecimiento de primas a la producción relativamente sustanciosas ${ }^{13}$. En el hiper, tienen también esa función los comple-

13. Al margen del papel que puedan tener en esa dirección las reuniones sobre cal idad que cele bran los principales directivos con los técnicos. 
mentos salariales que se atribuyen a los diversos niveles que se establecen dentro de cada grupo profesional, según el cumplimiento de determinados parámetros que juzgan los respectivos jefes de sección. Pero, en gran medida, la formación que se imparte a diversos colectivos, como las cajeras, no hace más que reforzar el seguimiento de tales parámetros; de modo que, finalmente, puede entenderse que los complementos salariales se obtienen a través de la formación y de lo que ésta puede comportar para lograr más fácilmente aquel seguimiento. Además, los propios mandos perciben complementos salariales por el cumplimiento de los objetivos marcados, pero, al mismo tiempo, la formación que reciben actúa como un elemento de integración y de refuerzo de identidad que pretende actuar como factor de motivación en el trabajo.

\subsection{Promoción en el trabajo y significados de la formación}

Las promociones son muy escasas en las dos empresas. C uriosamente, el $44 \%$ de quienes responden a la encuesta en el hiper afirman haber promocionado. Esa paradoja se explica en razón de que se considera como tal ascenso el hecho de haber pasado de contar con un contrato temporal a uno fijo sin que, en realidad, se produzcan aumentos de categoría.

En la práctica, la promoción o la estabilización en el empleo parecen depender de dos aspectos, los contextuales y los personales. Los contextual es estriban en las vacantes producidas por jubilaciones, bajas o por movilidad interna; también dependen de las expectativas empresariales respecto al mercado. Los aspectos personales tienen que ver con que exista disposición e implicación del trabajador, con que muestre motivación por el trabajo, identificación con la empresa y capacidad de aprendizaje o, mejor, de adaptación. Asimismo, llama la atención que los directivos entrevistados adjudiquen estas virtudes de entrega personal a los trabajadores temporales, porque ponen «ilusión».

La temporalidad en el empleo ha sido tan importante en nuestro país, y desde luego en el entorno de las empresas estudiadas, que se ha llegado a identificar el hecho de pasar de acumular contratos temporales a un contrato estable como una promoción. No cabe duda que la temporalidad tiene una importante función disciplinaria y, en un contexto de precariedad laboral, la ideología formación/promoción encuentra su caldo de cultivo. Pasar por un curso de formación adquiere el significado de transición ritual hacia un empleo estable: en el hiper ésa es la perspectiva del $75 \%$ de quienes dicen haber promocionado y, al mismo tiempo, aseguran que la formación recibida ha influido en ello. Para las empresas si esos cursos están subvencionados, como ocurre en el hiper, la formación se convierte en una fuente de ingresos con las que desarrollar no ya políticas formativas, sino más bien de motivación y de integración.

Con todo, en las dos empresas existe un cierto mercado interno de trabajo vinculado a la promoción. Sólo para los niveles directivos y, en la empresa de aca bados, para los técnicos, se recurre al mercado externo. Por lo general, la promoción suele estar asociada al anteriormente tratado proceso de formación informal, acumulativo a través de los años. No debe extrañar, por ello, que uno 
de los requerimientos para promocionar, particularmente en la empresa textil, sea la «experiencia» y su asociada, la «antigüedad» ${ }^{4}$. Y es que, como hemos dicho, detrás de la antigüedad no sólo hay años, hay también conocimiento organizativo, además del propiamente técnico. Asimismo, los criterios de promoción habitualmente se apoyan en la observación de determinadas pautas de comportamiento, tales como la subordinación, obediencia, disciplina, puntualidad, etc. Además del género, que se constituye en una variable claramente discriminatoria en términos de promoción y, en general, de empleo.

En efecto, en ambas empresas los hombres ocupan total (en la textil) o muy mayoritariamente (en el hiper) los puestos de nivel superior y son quienes pueden acceder a las escasas posibilidades de promoción que existen. La discriminación en el trabajo por razones de género se evidencia en las dos empresas. En la de acabados, como ocurre en el conjunto del sector, las mujeres están casi excluidas del empleo; y las pocas que existen son conscientes, como la entrevistada ocupada en el laboratorio, de que «nunca ascenderé aquí porque soy una mujer». Por contra, en el hiper la mano de obra femenina es netamente mayoritaria, el $70 \%$ de la plantilla. Pero las mujeres ocupan las categorías inferiores, se les asignan funciones específicas (cajeras) y, por ejemplo, sólo suponen el $17 \%$ de los puestos de jefe de sección.

En definitiva, en los casos estudiados la política de promoción no es importante. Tiene un carácter circunstancial y ocasional. Y más que de política habría que hablar de prácticas de promoción que se emplean en momentos ocasionales, ya que las vacantes disponibles son limitadas. En este sentido, las empresas, conociendo la limitación de puestos de trabajo de niveles superiores, suelen hacer un uso ideológico del papel de la formación continua. La formación que imparten tiene un significado que va más allá del estrictamente técnico, como el reciclaje o el adiestramiento a las nuevas tecnologías o procedimientos. El discurso empresarial de la formación suele estar asociado a la idea de modernización, de adaptación a los cambios tecnológicos y organizativos, pero también a veces es un mero discurso ideológico de modernización: como una forma de tensión, de alerta, de exigencia de estar al día, para disciplinar y movilizar la disposición y la voluntad de la fuerza de trabajo. En cierto modo, es también una forma de justificar que se hace al go ante las críticas del propio empresariado hacia las capacidades frente al trabajo de que dota el sistema educativo. 0 tras veces, la formación permite ritualizar el acceso al empleo, como ya hemos indicado al afirmar que la formación adquiere ese significado de rito de transición.

En otros casos, la formación adquiere el significado de distinción, de símbolo, de estatus. Es la que se proporciona preferentemente a los cuadros medios

14. Para el grueso de trabajadores el máximo aspirable es el puesto de encargado. En el paso de peón a oficial la promoción supone cierto adiestramiento, aprendizaje y aptitud en el puesto de trabajo, sin ninguna exigencia de formación formal. En el paso a oficial de primera se acentúa la necesidad de conocimientos especializados y, sobre todo, de ciertas capacidades comportamentales. Éstas últimas se exigen todavía más para llegar a encargado, junto con antigüedad, experiencia y, además, lealtad e integración con los intereses de la empresa. 
y a los directivos. Tiene, entonces, la función simbólica de reforzar el estatus y la autoridad de la jerarquía, pero también permite cohesionar la estructura de mandos mediante la configuración de una identidad colectiva. La convivencia en lugares donde se imparte - y comparte - la formación, cursos de fin de semana, cursos que implican viajes, alejarse del día a día del trabajo: todo ello confiere distinción e identidad frente a los demás a los pocos miembros elegidos. D e hecho, la formación destinada a estos niveles medios y superiores de la empresa, y que en nuestra investigación se constata para el caso del hiper, suele tener un contenido que trata de reforzar el estatus y la autoridad: dinámica de grupos, técnicas de comunicación y persuasión, liderazgo, etc. También es una formación identitaria: desarrollando la cultura de empresa, modos de dirección, estilos de trabajo, objetivos estratégicos; así como otros val ores que subrayen la identidad del colectivo de dirección y la distinción respecto al resto de la plantilla excluida de esos procesos.

\subsection{D iferencia entre la formación exigida y los requerimientos de los puestos de trabajo}

En relación con los requerimientos de los puestos de trabajo, hay que señalar que la mayoría de ellos está racionalizado de manera burocrática, con una definición normativo-prescriptiva de las funciones y tareas. Están pautados de forma taylorista. D e ahí que buena parte de las exigencias de los puestos de trabajo estriben en el seguimiento de las normas y pautas establecidas para cada tarea; lo que se suele aprender en corto espacio de tiempo. Esta forma de racionalización del trabajo ha sido una tendencia secular a lo largo del presente siglo y hoy se extiende tanto al ámbito de la industria como de los servicios (véase Ritzer, 1996). La aplicación de criterios tayloristas al trabajo es hoy cuestionada, incluso desde la perspectiva empresarial. En las empresas que hemos estudiado está, sin embargo, bien presente. M ás aún, cambios recientes en la organización de la producción y del trabajo en la textil, apuntan al reforzamiento de esos criterios en detrimento de formas de trabajo más autónomas, propias del trabajo de oficio hasta hace muy poco bien visible en la empresa para determinados puestos de trabajo. En términos de formación, obvio es decir que la simplificación de las tareas reduce drásticamente los procesos formativos de la fuerza de trabajo.

D e este modo, en la mayoría de los puestos de producción directa de la empresa de acabados y de los del hiper (tareas de reposición, atención al cliente, cajeras, etc. ), las exigencias funcionales educativas son básicamente de lecto-escritura. Saber leer y escribir es un requisito básico para la comunicación interna y la aplicación de las normas de trabajo. M ás allá de estos reque rimientos se requieren habilidades muy específicas que sólo se aprenden haciendo el trabajo, a través de la transmisión informal de conocimientos, de aprendizajes tutorizados por compañeros más experimentados o «antiguos», por medio del control y supervisión ejercido por el superior y a través de la interacción con otros trabajadores. 
En el caso del hiper, se pueden apreciar dos elementos que conforman los requerimientos de cualificación del puesto de trabajo. U no es la capacidad de autoorganización y otro, la precisión en el cumplimiento de las normas de trabajo. En el caso de las cajeras se exige, además, capacidad de relación y amabilidad con los clientes; elemento que, junto con la importancia del estricto cumplimiento de las normas (para evitar descuadres, por ejemplo), explica la formación formal que también reciben en la empresa. En la firma de acabados prima también la precisión en el cumplimiento de las normas (69\% de las respuestas). Esta exigencia de cumplimiento normativo de las funciones adjudicadas a cada puesto de trabajo varía según cada categoría laboral. En particular, es muy fuerte para administrativos y trabajadores de producción de bienes o servicios, y es menor para los técnicos y mandos, aunque también es notable. Para éstos últimos, los requerimientos de cualificación se refieren a capacidades organizativas, dotes de autoridad y capacidad de decisión. Concretamente, para los mandos del hiper aquellas exigencias se refieren a la capacidad de decisión (80\% de los casos), iniciativa y creatividad. Pero, como parece observarse en otros estudios (véase M asjoan y otros, 1996), son también este tipo de asalariados quienes en mayor medida sienten que están sobreeducados para el trabajo que realizan.

Por otra parte, los puestos de trabajo relacionados con atención al público tienen otros requerimientos de cualificación que no suelen adquirirse en el sistema escolar. Se trata de capacidades emocionales y comportamentales: autocontrol, capacidad de comunicación verbal y corporal, empatía y capacidad de persuasión. Es decir, se trata de cualificaciones actitudinales y comportamentales que en parte se aprenden durante el proceso de socialización primaria, en las familias, en los círculos de amistad y en el transcurso de la vida cotidiana. No hay que desconsiderar tampoco la contribución de la escuela en esta formación comportamental. Ciertamente, la escuel a contribuye a este tipo de capacidades: conocimiento del lenguaje, hábitos, pautas regulares de comportamiento, estructuración del tiempo, regularidad, responsabilidad y respeto a la autoridad, entre otros aspectos. Asimismo, este aprendizaje también se puede mejorar y ampliar a través del desempeño del mismo trabajo.

Por consiguiente, podemos colegir que la gran mayoría de los puestos de trabajo de las empresas analizadas (peones, oficiales de producción, reponedores, cajeras, vendedoras, trabajos de pastelería, etc.) no exigen cualificaciones efectivas altas'15. Q uizás en muchos casos sean suficientes los estudios primarios de lectura y escritura a tenor de la división técnica del trabajo existente y a sabiendas de que el aprendizaje se acabará haciendo en el trabajo16. Pero

15. Aunque, como hemos visto en los capítulos destinados a las empresas, al gunos trabajadores que ocupan esos puestos, como el reponedor entrevistado y observado en el hiper, o la pastelera del mismo, desempeñan tareas no estrictamente contempladas en su función laboral que exigen, por lo general, alguna capacidad complementaria, aunque en ningún caso de gran calado.

16. Una vez más, podemos observar la importancia que tienen los mercados internos en la construcción de las cual ificaciones. Ésta es singularmente una característica del mercado de trabajo español (Pries, 1988). Precisamente esta construcción de las cualificaciones en los 
en ocasiones tampoco viene mal a las empresas disponer de una oferta de fuerza de trabajo sobreeducada por el sistema escolar. Eso puede ser garantía de posibles capacidades que, de manera incierta, pueden llegar a utilizarse: buenos modales, capacidad de comunicación verbal y relacional y otras habilidades. No obstante, la cuestión de fondo es la abundancia de mano de obra sobre educada por la extensión del sistema escolar, la generalización de la enseñanza secundaria y, en especial, por la configuración de procesos de trabajo que definen puestos con escasas exigencias de puesta en juego de conocimientos y capacidades, de control y de autonomía en el propio trabajo. Es decir, con pocas exigencias de cualificación efectiva.

Los requerimientos de cualificación en el trabajo para los directivos y niveles medios pueden ser algo diferentes. Las tareas de coordinación exigen ciertas capacidades de abstracción, sistematicidad, ordenación, tenacidad y constancia para conseguir determinados objetivos. También pueden exigir ciertas dotes de autoridad para ser obedecido por los subordinados, tal como se ha visto en las empresas estudiadas. Estas capacidades puede proporcionarlas la enseñanza secundaria, complementada con un aprendizaje en el trabajo y acumulando experiencia. En el caso de la estructura de mandos medios, la sobreeducación respecto al desempeño del trabajo es menor que en el caso anterior de puestos de baja cualificación efectiva. Pero cuando se contrata a titulados universitarios para estas funciones, el desfase entre educación y puesto de trabajo puede hacerse clamoroso; y más aún cuando ocupan puestos de categorías bajas, como sucede con al gunas tituladas que ejercen de cajeras en el hiper. A la larga estos titulados pueden acumular frustración y desapego hacia su trabajo, especialmente si no tienen expectativas de promoción laboral.

\section{Trayectorias vitales y estrategias laborales}

\subsection{O rigen social y capacidades formativas: la formación reglada}

A diferencia de los epígrafes anteriores, donde exponíamos los criterios de reclutamiento y selección desde el lado de la demanda y en concreto de la empresa, ahora se trata de captar la valoración del papel de la formación desde el lado de la oferta: desde los asalariados. En particular se trata de recoger la percepción subjetiva que tiene la formación reglada en personas que, en sentido amplio, podríamos caracterizar como pertenecientes a la clase trabajadora.

En efecto, aunque con matices, todas las personas entrevistadas y cuyos puestos de trabajo hemos observado pueden ser ubicados en esa clase social. Todos son asalariados, aunque un par de ellos desarrollan funciones de mando; lo que, en términos de relaciones de trabajo, cabría hipotetizar que puede proporcionar una perspectiva distinta sobre las funciones y valor de la formación. I gualmente, el origen de clase de los entrevistados se sitúa en la órbita de la

mercados internos y su falta de certificación y reconocimiento institucional dificulta su transferencia entre empresas. 
clase trabajadora, con un par de excepciones relativas donde quizás cabría hablar de «situación contradictoria de clase» al ubicarse en la frontera con la clase media. Para el jefe de sección entrevistado en el hiper caben ambos matices y, además, es el único entre los entrevistados que cuenta con titulación universitaria. Por ambas razones su perspectiva sobre la formación difiere en alguna medida de la del resto de entrevistados, si bien su percepción subjetiva - y diáfana - de pertenencia a la clase trabajadora difumina parte de esas diferencias. En cualquier caso, se aprecia una considerable homogeneidad en las percepciones de las personas que aquí tratamos repecto a la formación.

\subsubsection{O rigen de clase: condicionantes estructurales}

La adquisición de conocimientos a través de la formación reglada está fuertemente condicionada por el origen social. En particular por condicionamientos socioeconómicos y por la subcultura de clase. El condicionante económico constituye un papel importante en la movilización de la fuerza de trabajo. LoS bajos niveles de renta en la unidad familiar empujan a los jóvenes de clase trabajadora a incorporarse lo más pronto posible al mercado de trabajo. «G anarse la vida» constituye una prioridad vital para ellos y sus familias. Los jóvenes comienzan a trabajar con objeto de contribuir a los ingresos familiares. Pero también, como constatamos en parte de las entrevistas en profundidad, para obtener independencia vital y económica. El abandono de los estudios tiene, en ocasiones, que ver con esa cuestión. Por contra, para el único titulado universitario, su nivel educativo es sentido como fuente de distanciamiento parcial de las preocupaciones e intereses de un nucleo familiar al que en absoluto renuncia por ello.

Las propias condiciones económicas, que facilitan el abandonar los estudios y ponerse pronto a trabajar, condicionan el futuro laboral y educativo. No es extraño, así, que los abandonos escolares se den particularmente en el bachillerato, un nivel educativo que puede actuar quizás como filtro en el acce so a algunos empleos, pero que parece servir poco para acceder a puestos de trabajo con algún nivel de exigencias prácticas o especializadas. El peso de aquellos condicionantes tiene también que ver con el estatus y la situación familiar; de modo que las figuras y referentes laborales familiares están ligados a las realidades y posibilidades que proporcionan a las personas el entorno más inmediato. Tales realidades ofrecen unos modelos profesionales que se configuran como los más previsibles. Eso es bien visible en varias de las entrevistas en profundidad realizadas: aparece en ellas una cierta autolimitación, no siempre explícita, respecto a los propios proyectos laborales e incluso respecto a las expectativas respecto a la formación reglada. D e ahí que, por lo general, la universidad no constituya una meta.

\subsubsection{Género y subcultura de clase}

Los roles sociales, atribuidos al género tienen también un papel importante en la movilización de la fuerza de trabajo. Es posible distinguir dos estereoti- 
pos, uno masculino y otro femenimo, así como una clara división del trabajo - entendido en sentido amplio - asociada a ellos. El primero, tiene el rol de proveedor de ingresos económicos y su ámbito de actividad está en el mercado, en el ámbito productivo. En el imaginario colectivo se le presupone disponibilidad de tiempo (largas jornadas, disposición a realizar horas extras, empleos complementarios, etc.) en las actividades productivas; mientras que no asume responsabilidades directas en el ámbito reproductivo. El estereotipo femenino presenta, por el contrario, un rol centrado en el hogar y en las tareas reproductivas. Si bien la mujer puede incorporarse también muy jóven al mercado de trabajo, en el imaginario colectivo existe la expectativa de centrarse en actividades propias del trabajo reproductivo. En las mujeres que hemos analizado esta cuestión está bien presente como perspectiva deseable de futuro. Perspectiva a la que sin duda contribuyen las características, escasamente atrayentes, de los empleos que ocupan.

D e este modo, entre las mujeres de clase trabajadora, se mantiene y reproduce la concepción tradicional del trabajo productivo de las mujeres, según la cual este trabajo es considerado subordinado a las tareas reproductivas y a las necesidades familiares. Su proyecto central de vida gira en torno a la reproducción y la actividad laboral se percibe como complementaria o subsidiaria. Con todo, desarrollan una actividad remunerada, respondiendo a necesidades económicas familiares que casi obligan a ello, y esa actividad adquiere protagonismo en su vida. Pero la escasa socialización orientada hacia el trabajo remunerado, considerado como algo secundario en su imaginario, tiene claros efectos respecto a su trayectoria formativa y laboral. Algunas manifestaciones son la indefinición de expectativas de formación formal y, en el momento en que las ha habido, su orientación hacia tareas continuadoras de la actividad reproductiva. Tales acciones formativas no tienen como objetivo cualificarse laboralmente: se trabaja allí donde es factible hacerlo gracias a los contactos informales y donde las exigencias de una formación particular y formalizada no es importante. No es raro, así, que se decanten hacia empleos que, al menos en parte, presentan características de aquello para lo que han sido socializadas, el trabajo reproductivo.

En ese tipo de empleos (cajeras a tiempo parcial, por ejemplo), subordinan la jornada y el horario formativo y laboral a los ritmos del trabajo doméstico y familiar, aún y con problemas: se tienen que acoplar al horario de la empresa que a veces distorsiona el familiar. Además, las entrevistadas (con una parcial y relativa excepción) están preparadas para cobrar poco y para ofrecer gratis sus cualificaciones aptitudinales y actitudinales. Es decir, para que no se reconozcan las capacidades, saberes y actitudes proporcionadas por su socialización y por la asunción del trabajo reproductivo. Pese a no reconocerse socialmente, tales capacidades (capacidad de relación, atención a terceros, etc.) resultan útiles a las empresas que las contratan. Esta situación casa perfectamente con los requerimientos empresarial es para gran número de los empleos del tejido empresarial de la industria o de los servicios: puestos de trabajo eventuales y poco cualificados, en los que se busca adaptabilidad, bajos costes de 
la mano de obra y capacidades y actitudes derivadas de las tareas propias del trabajo reproductivo.

\subsubsection{I maginario y primeras percepciones sobre la formación reglada}

Los originarios de clase trabajadora, con la única sal vedad de quien ha alcanzado titulación superior, no muestran especial afecto al sistema educativo ni parecen tener especiales expectativas en la formación reglada. En general, tienen una visión instrumental al respecto, valorando en mayor medida los aspectos educativos que tienen un componente práctico que, en algún momento, puede servir para su inserción laboral, que conocimientos de tipo más abstracto.

Eso se refleja en las entrevistas de diverso modo. Así ocurre con la preferencia de algún joven por estudios de FP - y en su seno de los aspectos más practicistas- sobre el BU P o sobre la renuncia a plantearse estudios superiores. Sucede también así con personas de edad más avanzada, como en general los trabajadores de la empresa textil, donde se valoran particularmente los estudios con aplicabilidad laboral más que el nivel de los mismos. La ambivalencia con que contemplan la formación reglada, desde encargados a peones, es pal pable. Por un lado, reconocen que algo de formación va bien como cultura y que los estudios que han cursado, sean de primaria o de bachillerato, suponen un bagaje cultural y, al mismo tiempo, son importantes como credencial de entrada a las empresas. Pero, simultáneamente, opinan que esta formación no les ha servido para nada en sus empleos, en los que predomina la formación «a pie de máquina», la experiencia y el seguimiento de las normas. Conviene recordar, por otro lado, que percepciones de este tipo se vinculan a los datos que aportábamos al respecto en los capítulos destinados a analizar ambas empresas: menor nivel educativo en la empresa textil, con abundancia de estudios primarios - incluso algún encargado cuenta sólo con ellos- , parcialmente explicable por la mayor edad media de la plantilla.

Independientemente de las actividades laborales desarrolladas, la formación se entiende aquí como un elemento de valores más amplios que tienen que ver con los intereses y valores personales y con la configuración cultural de la persona. Pero al margen de esas situaciones, aquel valor práctico aparece incluso en el único caso en que se aspira a cursar estudios superiores en el futuro: un reponedor que cree así poder aspirar a un mejor empleo, aunque, en realidad, no exprime todas las posibilidades para cursarlos ni parece tan claro que, con ello, pudiera acceder a mejores empleos.

El género también incide en la valoración de la formación reglada. Por un lado, las mujeres suelen también abandonar los estudios por la presión de la carga de trabajo en el hogar de la familia (padres enfermos, cuidado de hermanos, desempeño de tareas domésticas, etc.). Por un lado, esta valoración se suele apoyar en la propia concepción de su futuro rol: la identidad profesional y el trabajo no constituyen prioridades en el imaginario colectivo ni en el estereotipo de la mujer de clase trabajadora. Por otro lado, y de modo subsi- 
diario, pueden verse obligadas a abandonar los estudios por la presión que ejercen sobre ellas las tareas reproductivas del ámbito familiar.

En buena parte de las entrevistas, se puede captar que la primera percepción de la formación reglada es eminentemente instrumental. Tiene un val or de cambio para acceder al empleo. D e esta primera etapa se suele valorar otras cuestiones, la pertenencia a grupos y las referencias socioafectivas, como la amistad y el compañerismo. No obstante, después, a lo largo de la trayectoria vital y a medida que se adquiere experiencia laboral, se va modificando la percepción y las expectativas en relación con la formación reglada. Se la vincula con posibilidades de promoción, de cambio de empleo y como certificación para obtener mejores ingresos económicos. Es decir, sigue primando una visión instrumental, aunque a veces acompañada de otros ingredientes, tales como una forma también de obtener prestigio, consideración social y elevación de estatus. Pero raramente la formación reglada tiene valor de uso, como mecanismo de adquisición de conocimientos válidos en sí mismos.

\subsection{Estrategias laborales: la formación «para» el empleo \\ y la formación «en» el trabajo}

¿Q ué papel tiene la formación reglada en las estrategias de acceso al empleo? En el imaginario colectivo la formación reglada puede ser a veces relativamente importante como valor de cambio, pero no aparece como determinante. Para el acceso al empleo se suelen valorar otras dos cuestiones de mayor significado estratégico. Por un lado, las relaciones, los contactos y sus influencias. Es decir, las redes sociales de parentesco, amistad y vecindad parecen tener un papel importante, que en muchos casos permite incluso el acceso al empleo a pesar de un temprano abandono de los estudios. Por tanto, en el ámbito de las familias esta estrategia se suele sopesar ante la opción de continuar los estudios 0 ponerse a trabajar, en tanto que se tienen parientes 0 amigos relativamente influyentes 0 con contactos de calidad ${ }^{17}$.

Las estrategias para acceder al empleo aparecen más o menos claras en las entrevistas. Sin embargo, si nos preguntamos en relación a quétipo de empleo se busca o qué profesión se prefiere, parece exagerado hablar de estrategias. La entrada en determinado puesto y empresa es simplemente fortuita. No se escogen ni se desarrollan estrategias para realizar una función laboral concreta. Eso es así para todos los casos estudiados sin excepción, de modo que la inserción laboral depende de las posibilidades del entorno, de los contactos de las familias y del azar. Dicho de otra manera, no hay una estrategia racional con arreglo a fines profesionales. El fin es fundamentalmente entrar a trabajar casi en

17. Las redes familiares parecen resultar más importantes para la movilización de trabajo de baja cualificación y para los jóvenes que buscan primer empleo 0 , mejor, primeros empleos, ya que suelen disponer de varios de corta duración en los primeros años de su inserción en el mercado de trabajo. Las personas más maduras y con experiencia laboral disponen, sobre todo, de contactos propios a partir de compañeros de empleos anteriores o del actual, vecinos y amigos. 
lo que sea. En ello sin duda influye la actual situación del mercado de trabajo, de la que dan cuenta las trayectorias de parte de los entrevistados, que han pasado por diversos empleos precarios, con escasa relación entre sí y con sus estudios, hasta llegar al empleo actual.

Por otro lado, parece existir en la subcultura de la clase trabajadora la idea de que lo prioritariamente importante en el trabajo es el cumplimiento, el esfuerzo, la puntualidad, la obediencia y la disciplina. El contenido del trabajo raramente satisface, lo que se acepta con resignación y poca sorpresa. Estas pautas se transmiten y se aprenden en el seno de las familias de clase trabajadora, y de ahí que alcanzar niveles altos de estudios reglados no se constituya en cuestión prioritaria. $\mathrm{H}$ ay que añadir, además, que las redes sociales que facilitan el acceso al empleo, al mismo tiempo, contribuyen a reforzar las pautas de autoridad, disciplina y obediencia. En el trabajo, el referente de parentesco, amistad o vecindad se convierte en una forma de coacción sobre el comportamiento, en una forma de presión de la comunidad sobre el individuo. En definitiva, las redes sociales refuerzan el paternalismo y el conservadurismo en las relaciones laborales.

Con todo, la formación, sobre todo en su vertiente informal de adaptación al puesto de trabajo, tiene un papel importante dentro de lo que en sentido amplio - muy amplio en realidad- podríamos calificar de «estrategias de permanencia en el empleo». En efecto, una vez en la empresa, los asalariados aprovechan los canales y procedimientos informales para desarrollar su función. En ocasiones, incluso para real izar tareas laborales que están más allá de lo estrictamente prescrito, como sucede con alguno de los entrevistados en el hiper. Con ello persiguen mejores expectativas de permanencia 0 , más rara y difícilmente, de promoción en el empleo; sin contradecir la máxima de lo que lo que prima es el aprendizaje de las tareas a partir de su propio desarrollo y ejecución.

En el imaginario de la clase trabajadora existe la noción de que el aprendizaje se hace y se consigue en el trabajo, desarrollando las tareas, lo que no excluye del todo la importancia y la necesidad de la formación reglada. $\mathrm{H}$ asta cierto punto así parece ser en la realidad laboral. El adiestramiento se suele obtener a través de la propia vida cotidiana en el trabajo, a través de las relaciones formales e informales. Buena parte del contenido del trabajo consiste en el aprendizaje de normas no escritas, de hábitos y costumbres que forman parte de la organización del trabajo o bien del comportamiento social y de las relaciones de jerarquía formales e informales que se transmiten entre los trabajadores en la empresa. Estas normas consuetudinarias no se enseñan expresamente, sino que se aprenden a través de los contactos, de las equivocaciones y del ensayo-error, o bien son incluso producto de pactos tácitos entre los propios trabajadores. De ahí la especial importancia del compañerismo y de los grupos informales como medios de transmisión del conocimiento técnico y organizativo.

También hay casos en que el aprendizaje de las normas es muy explícito. $\mathrm{H}$ ay que seguir un manual de instrucciones (como el de la operatoria con las máquinas en la empresa textil) o indicaciones precisas sobre como realizar las tareas, como organizar el puesto de trabajo, como relacionarse con los compa 
ñeros o bien como atender a los clientes (el caso de las cajeras del hiper). Por tanto, una buena parte del aprendizaje es de tipo normativo. Eso se aprende fundamentalmente en el proceso de interacción social en el trabajo y menos en la escuela.

\subsection{Experiencias vitales y revalorización de la formación}

La experiencia laboral y vital acumulada en el transcurso de los años parece quelleva a que los entrevistados reconsideren el papel de la formación reglada, como ya se ha indicado atrás. Q uizás ello sea el resultado de diversas influencias, tales como la propia presión de una sociedad meritocrática, el riesgo de desempleo, la valoración de los estudios reglados para promocionar en el empleo, así como la percepción subjetiva de que los estudios reglados pueden permitir una mejor ordenación de las ideas o bien comprender ciertos aspectos técnicos del trabajo.

A veces la propia empíria, la práctica acumulada, va exigiendo subliminalmente mayores exigencias de abstracción para comprender la propia tarea que se desarrolla o entender el proceso productivo. 0 tras veces se suele asociar los estudios reglados y las titulaciones con el reconocimiento de categorías laborales. Y en otras ocasiones se percibe subjetivamente que los estudios reglados constituyen una vía para adquirir mayor estatus social. Estas observaciones no deben extrañar, puesto que es sabido queel desarrollo de la personalidad y la maduración suele ir acompañado de necesidades de reconocimiento social y simbólico.

Con todo, la percepción básica no cambia: la formación reglada tiene un valor básicamente instrumental, como valor de cambio. Primero como una de las condiciones para acceder al trabajo. D espués, como una de las condiciones necesarias para promocionar o como una de las condiciones necesarias para cambiar - y mejorar - de empleo. Esta reval orización instrumental de la formación suele estar relacionada con la exigencia de mayores ingresos derivada de las nuevas necesidades de consumo ya en la etapa adulta, por ejemplo: compra de coche y, más adelante, compra de vivienda y formación de una familia. Pero, sin duda, también por la propia presión de la abundante oferta de titulaciones y certificaciones en el mercado de trabajo. D e forma paradójica, esa valoración no está reñida con la percepción de la práctica totalidad de los entrevistados de que están sobreeducados para las exigencias a que los somete su trabajo18.

18. H ay cierta sensación de frustración entre los entrevistados respecto a la adecuación entre su potencial formativo y los recursos efectivamente movilizados en su actual puesto de trabajo. En alguno de los trabajadores de más edad de la empresa textil, eso se traduce en un desencanto respecto al empleo y a la empresa, y en ningún caso se ve la formación como una posible sali ida a este conflicto. Por otra parte, hay trabajadores jóvenes que creen haber al canzado, con su nivel educativo actual, su techo en la empresa, y sus opciones pasan por una reval oración de la formación formal (obtener una formación universitaria, por ejemplo) que les sirva de credencial para acceder a puestos más cualificados en, más probablemente, otra empresa. D e todas formas, ninguna de las personas entrevistadas ha plasmado estos deseos en estrategias concretas, lo que, en realidad, parece reflejar cierto conflicto entre el proyecto de mayor formación formal y la consciencia de los límites de ese proyecto. 
D e esa percepción cabría deducir que se consideran ya capacitados en sus niveles educativos para acceder a mejores empleos. No es así. El discurso dominante respecto a la relación entre formación y empleo asocia las mejoras en la primera dimensión con las de la segunda, de modo que, aunque se constaten fenómenos de sobreeducación, sigue primando la idea de que a mayor educación mejor empleo.

M ás allá de esta valoración instrumental existen también otras consideraciones complementarias del papel de la formación reglada. En algunas entrevistas, y en notable menor medida, se evoca la formación como un valor de uso: en término de valores nobles y éticos, superiores y de prestigio, abstractos y culturales. Eso aparace básicamente entre quienes han cursado niveles más al tos de estudios reglados y, en esos contados casos, aparecen incluso valoraciones en términos humanísticos, de formación de la persona.

\section{Conclusiones}

Como hemos indicado atrás, en la introducción de este artículo, en el terreno de las conclusiones trataremos de responder de forma más precisa a los cinco grandes retos o problemas planteados que se desprenden del marco teórico. Esto es, primero, ¿cuál es el papel que tiene la formación reglada en el acceso al empleo y qué papel tiene el capital relacional en la intermediación entre oferta y demanda? Segundo, ¿cuáles son las diferencias entre la formación reglada, la formación exigida y los requerimientos de los puestos de trabajo? Tercero, ¿cuáles son los usos y significados de la idea de formación desde las empresas y desde los trabajadores? Cuarto, ¿es posible una reconceptualización de la idea de formación? y ¿qué implicaciones teóricas y prácticas comporta? Y quinta cuestión, ¿qué aporta esta investigación respecto a las teorías y el discurso dominante sobre la formación y su relación con el empleo?

\subsection{La formación reglada en el acceso al empleo y el papel del capital relacional}

La formación reglada tiende a tener formalmente un papel cada vez más importante. Su importancia procede de dos cuestiones. De un lado, de la creciente presión de una abundante mano de obra potencial con titulaciones y certificaciones académicas, derivada de la expansión del sistema educativo. Al mismo tiempo, su importancia se acrecienta en el contexto del desempleo estructural. Por otro lado, la creciente importancia de la formación reglada, como demanda formalizada, se deriva de la presión institucional, de los grupos de presión y asociaciones profesionales. C on todo, su validez estriba en que es un «mecanismo de preselección» de la fuerza de trabajo. Pocas veces es una exigencia real del puesto de trabajo. En otras palabras, por lo general las titulaciones y certificaciones educativas no se convierten en cualificaciones efectivas en el trabajo. 
Las empresas utilizan los niveles educativos como criterio para ordenar la cola de candidatos al empleo. También como mero indicador de supuestas capacidades: las mínimas de lectura y escritura; y otras capacidades raramente explicitadas, pero presentes en los criterios de selección, tales como la disciplina, obediencia, puntualidad, capacidad de abstracción y sistematicidad que se pueden desprender de los distintos niveles educativos. En todo caso, el acceso al empleo no parece estar determinado por el papel de la formación reglada. Por el contrario, la cualificación efectiva se construye en la empresa, mediante el aprendizaje técnico y el aprendizaje organizacional.

La intermediación y el acceso al empleo dependen más del capital relacional, de la calidad de los contactos y de las influencias de parientes, amigos y vecinos; especialmente para ocupar puestos pertenecientes a las categorías laborales inferiores. Las «referencias» que proporcionan a la empresa estas redes son el resultado de diversos elementos, como son la subcultura de clase, el paternalismo y clientelismo. Pero también tienen raíces estructurales, como es el tejido de pequeñas empresas, las costumbres generadas en las relaciones laborales, la solidaridad entre los miembros de la familia y la facilidad de comunicación y movilización de recursos por la proximidad entre hogar y empresa en un territorio determinado. Igualmente, el peso del capital relacional y de las redes sociales se explica como resultado de opciones estratégicas de las empresas, con objeto de reducir costes de rotación y conseguir relaciones de lealtad, confianza y cooperación favorecidas por esas redes.

Por otra parte, el papel de la formación reglada «para» el acceso al empleo se ve cuestionado por las prácticas sociales. En particular, las prácticas de la clase trabajadora. En la subcultura de clase el éxito académico no es tan importante, particularmente cuando se refiere a niveles educativos superiores. Con todo, la valoración de la formación reglada se da básicamente en términos instrumentales, como val or de cambio en el mercado y como fuente de oportunidades de movilidad en el empleo y de promoción en el trabajo. Aunque, frecuentemente, la práctica parece contradecir tales representaciones.

Esa misma subcultura de clase valora positivamente el aprendizaje a través del trabajo mismo y del compañerismo como medio de socialización secundario. El desempeño laboral constituye la vía real para adquirir experiencia y conocimientos concretos y útiles. Entre otras cosas, porque final mente los puestos de trabajo ya están definidos por la división del trabajo, se pautan de forma taylorista y se aprenden sobre la marcha: en la práctica laboral. En este sentido, la idea de «experiencia» expresa un valor subjetivamente singular para los trabajadores. El discurso meritocrático escolar no es crucial en la clase trabajadora ${ }^{19}$. Eso no quiere decir que se desdeñe; simplemente no se concretan ni se consideran las denominadas «estrategias de inversión en capital humano». Antes que tal opción calculadora y sofisticada en términos medios-fines,

19. En cambio, las ideas de la meritocracia escolar, que sostiene el funcionalismo, parecen más importantes para las clases medias. Especial mente porque las credencial es académicas tienen un papel importante en la promoción y en las aspiraciones de estatus de dichas clases. 
es más acuciante simplemente «ganarse la vida». Pero, además, se intuye que no hay correspondencia entre oferta de fuerza de trabajo con certificaciones escolares específicas y las cualificación efectiva puesta en juego en el lugar de trabajo. Las experiencias de búsqueda de trabajo transmitidas por las familias, dan cuenta de la valía del capital relacional que, finalmente, se sitúa en primer plano entre los elementos movilizados para acceder al empleo.

\subsection{Diferencias entrela demanda de formación y la cualificación efectiva}

Podríamos colegir la existencia de una sobreeducación de la fuerza de trabajo para desempeñar puestos con contenidos muy simples, que se aprenden en su mayoría con breves cursillos o, más frecuentemente, a través del adiestramiento «a pie de máquina». Esto es especial mente evidente en las categorías laborales bajas, tanto en la empresa textil como en el hiper. Sin embargo, parece menos evidente esta afirmación en el caso de las categorías de oficiales en la textil, donde se requieren unos conocimientos profesionales más específicos que, en cualquier caso, se obtienen por medio de la experiencia laboral. D e este modo, el aprendizaje a través del propio trabajo deviene siempre fundamental. A este tipo de adiestramiento, que no guarda relación con procesos de formación formal y menos aún reglada, se le ha concedido por lo general escasa atención en los estudios sobre el tema. $Y$ vale la pena subrayar, que es un mecanismo particularmente importante en los países de industrialización tardía, donde la construcción de las cualificaciones se basa más en los mercados internos de trabajo que en el sistema educativo.

Asimismo, el aprendizaje informal en la empresa es importante en términos de adquisición de pautas, hábitos y conocimientos de las normas de la organización. Este proceso de socialización secundaria requiere mucho más tiempo y es más o menos continuado en el tiempo. En definitiva, tanto el aprendizaje del contenido técnico del trabajo, como el aprendizaje normativo de la organización, están pautados acorde con una determinada racionalización laboral burocrático-taylorista; que define de forma muy concreta las funciones de los puestos. Por tanto, las exigencias y la demanda de cualificaciones no estriba tanto (o sólo) en saberes y conocimientos, sino en cumplir las normas que prescriben el trabajo y definen las tareas. D e ahí que la cuestión central pase a ser la disciplina y la obediencia, al menos para las categorías laborales inferiores, como condición para que la maquinaria organizativa funcione. De ahí, también, que la demanda de capacidades de liderazgo y de relación y conducción interpersonal para aquel funcionamiento se exija a quienes desempeñan puestos de dirección 0 , también y en otra dimensión, a los mandos intermedios.

Así, para este tipo de funciones las exigencias formativas se refieren a capacidades de abstracción, sistematización, autodisciplina y autoridad, con objeto de coordinar determinadas fases del proceso de trabajo o dirigir las actividades y las personas que las desarrollan. En estos casos, los perfiles de las titulaciones superiores no coinciden necesariamente con las exigencias de los puestos de 
trabajo, pero pueden ser útiles las capacidades generales que se les presupone. Cabe matizar que, en el caso de las titulaciones de marcado carácter técnico, la correspondencia entre titulación y función laboral es mayor, tal como observan algunos estudios (M asjoan y otros, 1996) y como hemos visto para los técnicos de la empresa de acabados.

Con todo, el problema de la sobreeducación de la mano de obra no está en el sistema educativo. El problema radica fundamentalmente en el lado de la demanda: en la división y racionalización del trabajo en las empresas a partir del cual se establecen los requerimientos de cualificación para los distintos puestos de trabajo, que en su abrumadora mayoría muestran una extrema pobreza respecto a tales requerimientos. D e este modo, hablar de la utilización «recursos humanos» continúa siendo un eufemismo, en tanto que el uso que se hace de la mano de obra en las empresas excluye la puesta en juego de todo el potencial de las personas en el trabajo.

\subsection{U sos y significados de la idea de formación}

A tenor de lo expuesto en las páginas precedentes, podemos inferir que el concepto de formación tiene distintos usos y adquiere distintos significados para las empresas. No se limita a la idea de formación reglada y meritocrática que proporciona el sistema educativo. El uso social de la idea de formación adquiere contornos más amplios y, sobre todo, difusos.

Un primer uso de la noción empresarial de formación es generalista e ideológico, en términos de modernización y disciplina de la fuerza de trabajo. En este caso la formación se relaciona con la innovación tecnológica y organizativa de las empresas, con el incremento de la productividad, la calidad y competitividad20. En términos ideológicos la formación es también un discurso de dominación, culpabilización y exigencia para poder «promocionar» a un empleo estable. Así, a lo largo de los últimos años, ese discurso, al tiempo que legitima a la formación, la convierte en un instrumento para disciplinar y tensar la predisposición de la fuerza de trabajo durante los períodos de reestructuración y reorganización. $D$ e forma que la idea de formación, reciclaje y adiestramiento aparecen asociados con la reclamación a los asalariados de una plena disponibilidad ante la incertidumbre de los mercados o inminentes cambios tecnológicos y organizativos. La idea de formación se blande como una espada ante las posibles resistencias al cambio o modificación sustancial del empleo.

20. Con esta concepción coincide, en buena medida, el discurso de las administraciones públicas en torno a la formación, y en menor grado, aunque sin que sea inexistente, el de los sindicatos. Según este discurso la formación debe servir para procurar a los (futuros) trabajadores unas cualificaciones adaptadas a las «nuevas exigencias tecnológicas», de modo que la formación formal se convierte en instrumento de «progreso económico y competitividad». Por otra parte, recordamos que estos aspectos se tratan mucho más extensamente en el epígrafe dedicado a la contextualización del discurso de los agentes sociales en torno a la formación. 
Así, se suele reclamar a los trabajadores la necesidad de una formación permanente, lo que implica estar alerta ante las exigencias de competitividad, calidad y modernizacion. Empero, en terminos efectivos, estas exigencias no son permanentes. Sólo se recaban cuando se introduce nueva tecnología, nuevos productos o nuevas formas de organización del trabajo. En otras palabras, en la práctica empresarial las exigencias de formación, reciclaje o mero adiestramiento sólo tienen lugar en periodos relativamente cortos, lo que no justifica el perentorio discurso de la necesidad de formación permanente.

En segundo lugar, el uso ideológico del discurso que relaciona formación y empleo está asociado a ritos de transición. La certificación de cursos de formación ocupacional o formación continua se convierte en el rito para el acceso al empleo o para la estabilidad en el mismo. En otras ocasiones la formación actúa como un factor de integración en la cultura de la empresa, no guardan relación con los contenidos del puesto en sí. D e este modo, la formación deviene un mecanismo de disciplina y selección de la fuerza de trabajo, así como para crear una bolsa de trabajo subvencionada con fondos públicos.

Un tercer significado de la idea de formación es el que se refiere a su uso como diferencial de estatus. Ésta es particularmente la formación ofrecida para los niveles directivos y para mandos y técnicos. Tiene entonces el cometido de reforzar los símbolos de distinción del poder. De ahí la presencia de cursos sobre técnicas psicosociológicas relacionadas con el liderazgo, la comunicación, la dinámica de grupos, etc. En cualquier caso, y finalmente, el verdadero proceso formativo es invisible. Es la formación informal sobre el propio puesto de trabajo, en el día a día, que pasa desapercibida. Pero su importancia es fundamental para el aprendizaje de las rutinas, de las prescripciones del trabajo, para conocer el estilo, los trucos y las habilidades que exige. Y también para el aprendizaje de las normas, reglas, leyes consuetudinarias y referencias simbólicas de la organización.

D esde el lado de la oferta y particularmente desde la perspectiva de los trabajadores entrevistados, la idea de formación reglada es prioritariamente instrumental. La formación se entiende como formación «para» el empleo, tanto para acceder como para cambiar de empleo o incluso - raramente- promocionar. Aunque inmediatamente hemos de señalar que esta noción instrumental no es la misma que sostiene la teoría del capital humano. En el acerbo de la subcultura de clase se sabe o se intuye que el mérito escolar y la titulación es insuficiente «para» acceder al empleo. El título o certificación puede ser una condición necesaria, pero no suficiente.

A parece pues aquí una contradicción evidente. En las representaciones de los trabajadores la formación reglada tiene un papel instrumental en términos de empleo. Abundan las opiniones de que con más alto nivel educativo se podrían optar a mejores empleos. Pero no encaminan sus acciones a hacer de esa opinión una estrategia consciente, apenas invierten en su propio «capital humano». Y, más aún, se sienten sobreeducados para las tareas que desarroIlan o las que han desempeñado en su trayectoria laboral. D e tal contradicción cabe concluir que el peso del discurso dominante sobre las relaciones entre for- 
mación y empleo ha calado ampliamente, incluso entre aquellas personas que más evidentemente han experimentado su poca veracidad.

\subsection{Hacia una redefinición del concepto de formación}

El concepto de formación efectiva, que no explícitamente, utilizado es multifuncional. En la práctica empresarial va más allá de la certificación acadé mica. Por formación se suele entender y valorar diversos elementos, como las capacidades comportamentales y actitudinales, la formación reglada, la no reglada, la informal, el capital cultural y el capital relacional, entre otras cuestiones que, a veces, tienen que ver con elementos atribuidos al género 0 , incluso, a la situación familiar. Es decir, las empresas valoran conjunta y diferencialmente según los puestos de trabajo todas esas acepciones y aspectos de la idea de formación. En esta línea entendemos, por nuestra parte, que el concepto de formación hace también referencia a conocimientos abstractos y técnicos, a saberes adquiridos a través del trabajo y a capacidades de tipo actitudinal y comportamental, adquiridos durante la socialización secundaria; así como a saberes subyacentes en el currículo oculto de las personas adquiridos a traves de sus experiencias vitales. En su aplicación en el trabajo productivo, la formación no es patrimonio exclusivo, ni probablemente prioritario, del sistema educativo.

En definitiva, el uso del concepto de formación, como una idea multidimensional, nos indica que la demanda del sistema productivo sobre el sistema educativo no puede ser precisa. Los requerimientos de formación de las empresas tiene también contornos difusos, de modo que no se exigen generalmente cualificaciones con perfiles muy definidos. Las empresas usan el concepto de formación con distintos significados que aluden a capacidades, conocimientos básicos, actitudes, disponibilidad y disciplina. En términos de adecuación entre formación reglada y empleo, esta lectura implicaría que el sistema educativo debería generar cualificaciones generalistas, con unos conocimientos básicos, complementado con la construcción de posibles perfiles profesionales, de forma que permita la adaptación de la fuerza de trabajo a requerimientos poco precisos.

Precisamente éste es uno de los retos que tiene el mercado de trabajo español: pasar de un modelo de construcción de las cualificaciones basado predominantemente en los «mercados internos» a otro «modelo profesional »21. En el primero, la construcción de las cualificaciones es muy dependiente del aprendizaje en la empresa y tiene, como efecto secundario, la falta de reconocimiento

21. En la bibliografía especializada (O sterman, 1988; M aurice, Sellier, Silvestre, 1987; M arsden, 1994, entre otros) pueden distinguirse básicamente dos modelos: el mercado de «trabajo interno», donde el aprendizaje depende de la empresa y el mercado de «trabajo profesional», donde el aprendizaje tienelugar entre el sistema educativo y la empresa. En este caso, particularmente, el rasgo distintivo es el oficio o profesión, cuyo reconocimiento institucional garantiza la transferibilidad en el mercado de trabajo. 
de las cualificaciones adquiridas. El reconocimiento depende de las decisiones de la empresa, de la organización del trabajo y de las propias relaciones laborales particulares. En cambio, en el modelo profesional, derivado de la cooperación entre instituciones formativas y empresas, las acreditaciones son oficios o profesiones reconocidas por todos los actores (empresarios, sindicatos y Administración pública), por tanto, se generan cualificaciones transferibles, que se pueden utilizar en una variedad de empresas, lo que podría hacer más transparente al mercado de trabajo.

D e todos modos, y más allá de las consideraciones anteriores, el aprendizaje y la adecuación al puesto de trabajo, se realiza en un segundo momento, en la socialización secundaria en el trabajo y en la organización. D e aquí también podríamos derivar la necesidad de una mayor cooperación entre el sistema educativo y el productivo, para propiciar una formación dual que facilite la construcción de perfiles profesionales polivalentes y coadyuve a la movilidad interna de la fuerza de trabajo, y con ello a reorganizar las formas de trabajo. Una reorganización que, además, es imprescindible si de verdad se quiere utilizar todo el potencial laboral de las personas sin quedarse en el terreno del discurso. Eso revertiría positivamente en términos de productividad tan queridos en las empresas. Pero paralelamente 0, mejor, por encima de ello, revertiría en el logro de una mayor humanización del trabajo productivo y en la obtención de dosis de satisfacción personal por parte de los trabajadores que, al fin y a la postre, son quienes lo desarrollan.

\subsection{Consideraciones teóricas. meritocracia y credencialismo}

D esde la década de los ochenta estamos asistiendo a una recuperación y a un nuevo auge de la teoría del capital humano, que subyace en el discurso dominante relativo a las estrategias para el desarrollo y la creación de empleo. La formación figura como elemento clave en las estrategias diferenciales de competitividad basadas en la investigación, la tecnología y la calidad22. Asimismo, la formación se plantea como propiciadora de la igualdad de oportunidades, del reciclaje, de la movilidad y promoción de mano de obra.

D esde los años sesenta la teoría del capital humano ha venido sosteniendo que la formación (en su acepción más formal y, por tanto, mucho más restrictiva que la que hemos concretado en esta investigación) tiene un papel importante en la igualdad de oportunidades y, por ende, en la reducción de las desigualdades sociales. Sin desmentir esa argumentación, hemos visto como el imaginario de personas pertenecientes a la clase trabajadora limita las expec-

22. Véanse, por ejemplo, los planteamientos de competitividad internacional que desarrolla la política socialista durante los años ochenta (C arles Boix, 1996). D esde este periódo se viene argumentando que la estrategia de competitividad diferencial de la economía española tiene que basarse en la investigación, en la innovación tecnológica, en la calidad y no en la reducción de costes laborales. Esta opción estratégica comporta una creciente inversión en capital humano, la reforma de la formación profesional, el desarrollo de la investigación y la generación de titulaciones. 
tativas educativas de sus miembros. Pese a que, además, también la práctica educativa muestra esas limitaciones, en los noventa aquella concepción vuelve de nuevo a orientar también la política institucional: es el caso, entre otros muchos, de la FO RCEM, que afirma la importante función de movilidad social que tiene la formación en la era de la sociedad del conocimiento y de la información.

Sin embargo, en la práctica se desmiente estos supuestos. La «sociedad del conocimiento» se concreta en puestos de trabajo donde la aplicación de los mismos es escasa. Además, las políticas de formación de las empresas tienen un marcado carácter dualista y selectivo. Las inversiones en formación se dirigen preferentemente al núcleo de empleo que ya cuenta con altos niveles de formación reglada inicial. Es decir, tiene una clara orientación segregadora, diferenciadora y, por tanto, ahonda las desigual dades sociales de partida.

Esa cuestión ha quedado evidenciada en nuestra investigación, tal como habíamos podido colegir de otras anteriores ${ }^{23}$. Las políticas empresariales de formación no se dirigen al conjunto de los trabajadores, sino a los escasos beneficiados de los procesos de cambio en el ámbito empresarial. Los perdedores, los trabajadores con bajo nivel educativo inicial, se ven excluidos. También se ven excluidos todos aquéllos que, independientemente de su formación reglada, desarrollan tareas que comportan pocas exigencias en términos de cualificación. $Y$, cuando se les destina al guna formación, ésta tiene poco que ver con los requerimientos laborales, y el aumento de capacidades en ese orden que proporciona es harto dudosa 0 , simplemente, desdeñable. Por tanto, podemos colegir que las políticas empresariales de formación no brindan verdaderamente la supuesta «igualdad de oportunidades», tal como se desprendería de la teoría del capital humano e incluso tal como se recoge en la letra del Acuerdo $\mathrm{N}$ acional para la Formación C ontinua (D e la Torre, 1997). Es más, la formación como impulsora de mejores condiciones de empleo en la empresa que la proporciona también se ve limitada por las escasas oportunidades de promoción. U na promoción que, como hemos visto, está supeditada a las escasas vacantes que se producen y en la que tienen mucho más peso que la formación formal, reglada o no, otros elementos como la experiencia y, sobre todo, capacidades comportamentales entre las que destacan la confianza y la lealtad a los criterios empresariales.

En todo caso, la formación reglada puede tener un papel en la movilidad de la fuerza de trabajo, en el reciclaje y la recolocación de la mano de obra excedentaria desde sectores reestructurados a otros emergentes. Pero no en la promoción ni en la igualdad de oportunidades. En otras palabras, su acepción como elemento aportador de «igualdad de oportunidades» es seriamente cuestionable, cuando no mera ideología. Eso no significa de ningún modo que la formación carezca de importancia. En el peor de los casos sirve para ordenar y jerarquizar la cola de quienes buscan empleo o bien como criterio de preselección en la contratación. 
M ás allá de estas observaciones empíricas, la formación fundamentalmente comporta capacidades y conocimientos que el ámbito productivo no utiliza. Por eso estimamos erróneo empeñarse tozudamente en la idea de la «correspondencia» 0 «conectividad» entre formación y empleo. El reto no es sólo modificar el sistema educativo, sino fundamentalmente transformar la organización del trabajo en el tejido productivo para aprovechar mejor las capacidades y los conocimientos generados en el ámbito educativo. Y, desde luego, para aprovechar mejor (las empresas) y poder poner en juego (los asalariados), las capacidades adquiridas en otros ámbitos y que en la práctica revierten también en el trabajo.

\section{Bibliografía}

Boıx, Carles (1996). Partidos políticos crecimiento eigualdad. M adrid: Alianza Editorial. Bow LES, G intis (1983). «La educación como escenario de la reproducción de las contradicciones capital-trabajo». Educación, 2. M adrid.

Co LLINS, R. (1989). La sociedad credencialista. M adrid: Akal.

GRUP D 'EsTUDIS Q UIT (1997). Economía, trabajo y empresa. M adrid: Consejo Económico y Social.

ESPIN A, Álvaro (1997). «La formación técnica postsencudaria y la competitividad de la economía española». REIS, 77-78: 69-115.

LOPE, A.; M ART ín ARTILES, A. (1993). «C ambio técnico y recualificación. Formación y adquisición de las cualificaciones en la empresa». Sociología del Trabajo, 19: 69-98. Madrid.

- (1995). «Las relaciones entre formación y empleo». Economía y Sociología del Trabajo, 27-28: 254-266. M adrid.

LUCAS M ARín, A. (1997). «La formación para la participación y la comunicación en las organizaciones》, REIS, 77-78: 263-280.

O STERM AN, P. (1985). Los mercados internos de trabajo. M adrid: M TSS.

M ARSDEN, D . (1994). M ercados de trabajo. M adrid: M TSS.

M ASJUAN, J.M . y otros (1996). La inserció professional dels nous titulats universitaris. Barcelona: ICE-UAB.

M artín ARTILES, A.; LoPE, A. (1994). «D inámica de las cualificaciones y política de recursos humanos». Economía y Sociología del Trabajo, 21-22: 115-128.

M artín Art ILES, A.; M IGUélez, F.; PAStor, I. (1996). «C atalogna: Le risorse umane in un del mercato lavorodual istico». En REGINI, M. (ed.). La formazione delle risorse umane. Bolonia: II M ulino.

M AURICE; SelLier; Silvestre (1987). Política de educación y organización industrial. Madrid: M TSS.

M O REN O, F. (1997). «Aprendizaje organizativo y generación de competencias». REIS, 77-78: 247-261.

PABLO, A. de (1997). «La nueva formación profesional: dificultades de una construcción». REIS, 77-78.

Prieto, Carlos (1989). «Políticas de mano de obra en las empresas españolas». Sociología del Trabajo, 6: 33-50. M adrid.

- (1992). «C ambios en la gestión de la mano de obra: interpretaciones y críticas». Sociología del Trabajo, 16: 77-102. M adrid. 
PRIES, L. (1988). «La transformación del trabajo industrial en España y en la RFA». Sociología del Trabajo, 2: 81-100. M adrid.

ReQuen A, F. (1990). Redes socialesy mercado de trabajo. M adrid: CIS.

RITZER, G. (1996). La M cdonalización de la sociedad. M adrid: Ariel.

TO RRE, Isabel de la (1997). «La formación y las organizaciones. Los acuerdos nacionales de formación continua». REIS, 77-78: 15-33.

W ILLIS, Paul (1988). «Aprendiendo a trabajar». M adrid: Akal. 